sufficient data. This, however, seems to be certaio, that if conception takes place at a period when the father has recovered from local symptoms, but is sufferiog from what are generally known as secondary sy mptoms, such as present themselves during the six months which follow the time of inoculation, the mother will exhibit more or less wellmarked evidences of infecion, and that these closely resemble, if they are not ideutically the same as, the secondary symptoms present in the father. To prove this fact iz, of course, ouly possible from complete cases-that is, from acsurate details of the condition of $b$ th parents, and particularly of the male parent. The probability of marriage taking place when a man is suffering from active secondary symptoms is, it is almost unnecessary to say, very small, and for this reason data of the kind referred to are few. But as far as they go they prove what I have stated, and lead us to conclude that we must look to the state of the father for an explanation of the various effects produced both upon the mother and the fotas.

In putting forward this view, which is quite an old one, I am ready to admit that we require more data to establish it, but I must point out to you very clearly that there is no evidence against it. All that has been done hitherto ha been little better than surmise, so far, at least, as published statementy go in this respect. The cases of Mr. Hutchinson throw no light upon this particular question, and unless it be made a special subject of inquiry, short histories of case of family syphilis would be useless for our purpose. If you analyse Mr. Hutchinson's thirty-six cases you will see that a certain and considerable number are cases of primary in fection. In a certain number of cases no symptoms had shown themselves in the mother, and these consequently are of no use. We have left the cases where the mother has suffered more or less, but in the histories of these no sufficient account, if any at all, is given of the father. The only case is No. 5, and it is doubtful what happened. Mr. Hutchinson is in difficulty, and cannot explain the statements made. This, I think, shows the importanse of further research in the direction indicated. I can only tell you what conclusions have seemed to me probably true from the impartial study of such cases as we have at this hospital.

I would now ask your attention to some of the points which appear deserving of consideration as they present themselves in our practice here. There is, first, the variety of symptoms which syphilis assumes in the infant and young child. I do not see how to classify these, or divide them consistently with their probable cause; we cannot speak of such phases in the disease as we designate by the terms primary, secondary, and tertiary. We certainly see very decided differences in the local and constitutional symptom*, and we nnderstand what is meant by an infant having congenital syphilis very badly indeed, or by its having it very slightly. When symptoms of the disease appear very soon atter birth they are of a tolerably constaut character, and are different from those which appear later; so that we may speak of early and late symptoms. The early are those with which we are all familiar, the most marked being the peculiar cachexia and the symptom of snuffing. The late symptoms are fewer, and occur more rarely than might be expected. The most characteristic are the condyloma an $i$, and the syphilitic furuncle or gumma, beginning as a nodule deeply seated beneath the :kin, and gradually as it approaches the surface becoming softer, and indicating its existence by a bluishred colour of the skin, with slightly elevated surface, and with little or no pain. These later symptoms sometimes show themselves in infants who have previously suffered from the early symptoms, and sometimes, and quite as frequently, they are met with where no previous symptoms have existed. The parts of the body where the furuncles occur are generally the buttocks and posterior aspects of the thighs, and they are frequently more or less symmetricalthat is, they appear in corresponding localities on both sides about the same time.

I think that the clinical study of the symptoms I have thus briefly mentioned will lead to the conclusion that the first set, the more serious, are generally associated with a history in the father of rather recent infection, whether the mother has shown symptoms of infection or not; and that the latter, the less serious, when the date of infection in the father is more remote, and the mother has shown no sym ptoms whatever; at least, that this is true of those cases where the child has had none of the serious symptoms previously.
EXCISION OF THE ENTIRE TONGLE, LEFT TONSIL, AND PART OF THE VELUM PALATI FOR CANCER. ${ }^{1}$

BY KENDAL FRANKS, M.D. UNiv. DUb, F.R C.S.I., SURGEON TO THE ADELAIDE HOSPITAL, SLRGEON TO THE DUBLIN THROAT AND EAR HOSPITAL.

I Do not think it is necessary at the present day to defend the practice of total excision of the tongue when it un. fortunately becomes the seat of cancer. The condition presented by a patient suffering from the disease is such that any operative procedure which can hold out even a hope of relief from the constant and agonising pain seems to be now gentrally recognised as justifiable. The dangerous character of the operation itself, the fear of hæmorrhage, both imme. diate and remote, the spectral form of septic infection, all of which threaten to put a speedy termination to the patient's life, should not weigh too much with the surgeon, and generally weigh but little with the patient, when the alternative is only to look for ward to that state in which, as Mr. Erichsen so forcibly puts it, "nothing can exceed the misery of the patient's aeath, brought about as it is by pain, hæmorrhage, and starvation." Such considerntions, fortified by the urgent entreaties of the sufferer himself, induced me to operate in the following case. I do not intend in this paper to enter into a discussion on the various methods of operating, or to eudeavour to determine their relative merits; but I will premise this much, that my experience of the use of the galvano-cautery in this case is not of a kind to induce me to join in the chorus of condemnation with which it is so often received. For the notes of the case I am indebted to Mr. Bewley.

J. P- aged forty-five, a foreman on the Midland Great Western Railway, was admitted into the Adelaide Hospital on December lith last, under my care. He had enjoyed good health till about three years ago, when he began to suffer from neuralgia over the left eye. Of this he was soon relieved by leeching, and he remained in good health afterwards till about seven months ago, when he first noticed a hard gland, just behind the left angle of the jaw. It gradually increased in size, but was then neither painful nor tender. Towards the end of last October he noticed that whenever he swallowed he felt pain in the floor of the mouth between the hyoid bone and the sympbysis menti. This first came on after a wetting, to which he attributed it. $A$ bout six wetks previous to admission he observed, by examining his mouth in a mirror, that there were two small raw spots on the mucous membrane covering the ascending ramns of the jaw on the left side. These were several times cauter ised with nitrate of silver, which gave him temporary relief. Since then the pain bad been on the increase, shooting from the left angle of the jaw, over the left eye, and back to the ear, and all over the side of the head. This had become so intense that he could hardly ever sleep. Swallowing became much more painful, and when admitt d to hospital his food was confined altogether to liquids. He had lost flesh rapidly lately. Within the last two months, prior to his seeking relief at the hospital, he had lost over a stone in weight There was no family history of cancer, and he had never had syphilis. When I first saw him he could with difficulty open his mouth owing to the pain at the angle of the jaw, where an enlarged and hard gland could be telt, which was tender on pressure; it was about an inch in length and situated immediately below the angle. On looking into the mouth the left half of the tongue was seen to be distinctly larger than the right, and was thickened and indurated to the touch. Any attempt to depress it in order to see its base caused great pain. This induration occupied the whole of the posterior half of the left side, and on examination with the laryngoscope an excavated ulcer with elevated edges could be seen at the posterior part facing the pharynx. The left tonsil was involved, and there were patches of the disease on the left half of the velum palati. There was a constant and profuse flow of saliva from the mouth, which caused him much uneasiness. He was most anxious that an operation should be done, and when I suggested to him that it might not be advisable owing to the risks involved in an operation

1 Read at the meeting of the Surgical Section of the Academy of Medicine of Ireland, March 7 th, 1884 
for such extensive disease, he became greatly distressed and said he would rather run any risk than continue to suffer as he then did. Accordingly, at the joint request of himself and his wife, and with the concurrence of my colleagues, I operated on the 8 th of January last in the following manner. As it was necessary to keep the patient in the upright position, and at the same time advisable that he should be able to second our efforts if required, I selected bichloride of methylene as the most suitable anæsthetic, and this was administered by means of Junker's inhaler by our surgical registrar, Mr. Scott. The face having been previously sufficiently shaved, I began by an incision at the left angle of the mouth and extending to the anterior border of the masseter muscle. This incision was slightly curved, being convex downwards. All bleeding points having been secured, the divided cheek was raised and held in this position by my colleague, $\mathrm{Mr}$. Warren. I then passed a strong curved needle, fixed in a handle and armed with silk, through the base of the tongue from side to side, as far back as possible. The loop of ailk having been seized with a forceps, the needle was withdrawn. By means of this loop of silk the platinum wire of a galvano-cautery écraseur was drawn through the base of the tongue, and made to encircle completely the attachments of the tongue to the floor of the mouth. 'The écraseur was then tightened up, and contact made. In less than three seconds the tissues embraced in the loop were completely divided, without the loss of a drop of blood. I then seized the tongue with a pair of vulsellum forceps, so as to draw it well forwards and upwards. The next step of the operation consisted in transfixing the floor of the mouth with a Worthington tracheotomy knife, which is provided with a movable director on its back. This was inserted in the middle line immediately above the hyoid bone, and was pushed steadily upwards and slightly backwards till it was seen to emerge inside the mouth underneath the tongue. The director on its back was then left as a guide in the wound and the knife withdrawn. Along the groove of the director I now passed the platinum wire, and, drawing it well upwards into the mouth, I made it encircle the base of the tongue before bringing the end back along the director through the submental incision. Before making the wire taut I pushed the loop well backwards till I could feel it close to the epiglottis. Contact being made, the wire passed as rapidly as before through all the tissues included in the loop, and again there was not a drop of blood from the divided stump. I now found that some of the disease remained in the stump between the epiglottis and the left tonsil, which was also involved. The platinum wire was now again brought into requisition. A needle armed with silk was made to penetrate through the stump from before backwards till its point could be felt close to the epiglottis, and it was brought back below the tonsil so as to encircle as much of the disease as remained in the floor of the mouth. This was so effected that as the platinum wire which followed the course of the silk was made to burn through the tissues its loop should pass well below the disease. There now remained in the mouth the involved portion of the left half of the velum palati and the left tonsil, which was cancerous, and to which was attached the portion of the floor of the mouth and stump which had just been separated by means of the galvanocautery. I now had recourse to a fine curved blade of Paquelin's thermo-cautery. The diseased tonsil and part of the soft palate were seized in an ordinary pile forceps, and by means of the thermo-cautery they were slowly excised. This necessitated the removal of more than half of the left side of the velum, the whole of the anterior pillar of the fauces, and the entire tonsil. I now had to deal with the only hremorrhage which occurred during the operation, subsequent to the division of the cheek. It was only trifling in quantity, and came from a small vessel in the palate close to the uvula. It was arrested by a small pledget of lint soaked in perchloride of iron. It is worthy of remark that the sections made by the galvano-cautery were from beginning to end entirely bloodless, while none of them occupied more than about three seconds. The edges of the incision through the cheek were then brought together by means of three harelip pins. The patient, as soon as the operation was completed, got up off the chair of his own accord, and almost without assistance walked across the theatre to the couch which was to convey him back to bed. The enlarged gland under the jaw was not removed at the time of operation, as it was considered that the patient had undergone enough for one day, but its extirpation was postponed till he had sufficiently recovered from the ordeal he had just undergone. As soon as he had returned to the ward, a hypodermic injection of one-sixth of a grain of morphia was administered.

The subsequent progress of the case can be shortly described. The temperature never rose above $99.6^{\circ}$, and was normal on the third day. On the eighth day there was a little bleeding, which came guttatim from the mouth. This was found to come from the same point in the palate which had bled at the time of the operation, and was easily arrested by the house-surgeon with a small pledget of lint soaked in perchloride of iron. It recurred, however, again on the fifteenth day, and I then seized the bleeding point with a pair of Spencer Wells's forceps, and left it in position for a couple of hours, when the hremorrhage was found to be completely arrested, and it never recurred again. It is worthy of note that there never was any hremorrhage from any of the parts divided with the galvano-cautery, either at the time of operation or afterwards, and now, two months after opera. tion, the greater portion of the raw surfaces is cicatrised except the posterior part, which has a granulating elevated appearance. Of a recurrence of the disease in this situation it is impossible at present to speak. The cheek wound healed by first intention, the pins being taken out on the fifth day. The patient's strength was supported during convalescence by nutrient enemata, chiefly composed of beef-tea, milk, and eggs, to each of which a teaspoonful of Benger's liquor pancreaticus was added. On the fourth day an attempt at swallowing beef-tea was accompanied by so much pain that the attempt was not repeated for nearly a fortnight, though on two or three occasions $I$ administered about a pint of strong beef-tea through a large sized catheter passed down into the cesophagus. He can now take soft and liquid food with comparative ease by the mouth, and this diet is supplemented still by enemata, The relief from pain which the patient has experienced is most marked and very encouraging. Except for the pain brought on by trying to swallow too soon, and headache, from which he suffered much for a few days after the operation, he has been quite free from it. The neuralgia over the side of the face and head has never returned, and he has expressed himself repeatedly as being very well, but very weak.

The local treatment consisted mainly in irrigating the mouth constantly by means of Thudichum's nasal douche with a solution of sanitas and water. The raw surfaces were mopped several times a day with equal parts of hazeline and water, and for the first week a steam-spray of sanitas was frequently allowed to play opposite the mouth. Since the operation there has scarcely been any foetor observable, and nothing like a regular slough ever came away. The increased flow of saliva from the mouth has almost completely ceased. The gland at the angle of the jaw was removed on Feb. 19th. Previous to operation it had felt like two glands, but when exposed it was found to be single, and slightly constricted near its centre, which gave the sensation of its being double. An incision was made about three and a half inches long, extending downwards and forwards from the lobule of the ear. It was curved slightly, being convex downwards. When the anterior border of the sterno-mastoid was reached, it was retracted backwards, and a little dissection brought the gland into view. It was attached posteriorly to the internal jugular vein in its whole length, and was carefully dissected from this with the finger nail. A small venous trunk was injured close to its entrance into this vein, from which there was some slight bleeding. It was ligatured above and below the injured spot with catgut, the distal ligature being applied at its junction with the internal jugular vein. The tissues were then brought together with catgut, and a small drainage-tube inserted. The wound healed by first intention, without suppuration or fever, the highest recorded temperature being $992^{\circ}$. Antiseptic precautions, according to Lister's method, were of course employed.

The patient has not lately progressed as well as I could wish. He complains much of weakness and is disinclined to get up, or to join in the recreations of the ward. He has also become silent, and is inclined to be irritable. $\mathrm{He}$ is, however, quite free from pain, and has often told me he would gladly undergo the operation again to be relieved of the agony which he endured before the operation was performed.

Before bringing this paper to a close-a paper necessarily incomplete as far as the ultimate result of the operation is 
concerned-I should like to say a few words as to the form of battery employed in this case. One of the great objections to the use of the galvano-cautery in all cases is the difficulty of obtaining an electrical apparatus on which one can depend. For some years I have been frequently in the habit of using the galvano-cautery in small operations about the mouth, nose, and throat, and in cases where some such powerful agent is required, nothing can equal for efficiency and painlessness the use of the white hot wire. But this instrument can never come into general use, as long as we are dependent in some form or other on the bichromate cells. Powerful as the bichromate battery undoubtedly is, the rapidity with which it becomes polarised, the difficulty and expense of always keeping it properly charged, and its liability to fail at the moment when it is most wanted, are drawbacks which to the minds of most men more than com pensate for its advantages. In my own practice I had almost completely abandoned the use of the galvano-cautery, and I was hoping that some other form of cell would be devised which would be more convenient for general and frequent use. Such I believe will prove to be the case with econdary batteries or storage cells. The special form employed in the case I have related was that devised by $\mathrm{Mr}$. Prescott of this city, who kindly lent me three cells for the occasion. These were charged by being placed in the circuit of a dynamo-machine for about half an hour. The manner in which they worked during the operation left nothing to be desired, and at its termination, the intensity of the current was not appreciably diminished. As I have had several opportunities of using them lately in smaller operations about the throat, owing to the kindness of $\mathrm{Mr}$. Prescott, I can speak confidently of their efficiency. The one drawback to them at present is that they do not hold the charge they have received longer than two or three days, at least not in a sufficient degree to employ it for surgical purposes, but I have no doubt that before long they will be improved in this direction. The galvano-cautery will then become more popular, and we shall then hear less of those evil consequences which are generally due to the inconveniences and uncertainties which have hitherto attended its use.

Mr. Prescott informs me that from several experiments made with these cells it has been ascertained that each cell when fully charged yields 4000 ampère minutes, equal to $66^{\prime} 6$ ampere hours-that is, it would yield a current at the rate of 66 ampères for one hour. The electro-motive force of each cell is $2 \cdot 1$ volts, the internal resistance being . $01 \mathrm{ohm}$. Three cells, as employed in the above case, yield, when joined together in a series, a current at the rate of 66 amperes with an electro-motive force of 6 volts for one hour.

Note.-Since reading the above paper, I have to record the death of the patient, which occurred quietly on March 16th. He gradually sank from exhaustion, with evidences in the floor of the mouth of a return of the disease. Up to the last moment of his life he was quite free from pain, and complained of nothing but increasing weakness. His condition precluded any hope of his being benefited by a second operation; but his peaceful and painless death when contrasted with the usual terminations of cases of cancer of the tongue, shows that even when the disease cannot be totally eradicated, much can be gained in the way of comfort for the sufferer by operative measures.

\section{REMARKS ON PERINEAL LACERATIONS.}

By GEORGE ELDER, M.D.,

SURGEON TO THE HOSPITAL FOR WOMEN, NOTTINGHAM,

IN treating of lacerations of the perineal body, I purposely exclude vaginal orificial tears, which, according to Dr. Matthews Duncan (vide Papers on the Female Perineum), are inevitable in the primiparous female, and also such rare accidents as central rupture; but confine myself to the more familiar, but not less important, lesions of contiguity ranging from mere slitting of the fourchette to rupture into the bowel. That these cases have at least not hitherto received that attention which they demand is shown by the large number of women who daily seek relief at our hospitals from sufferings due to this potent factor of uterine mischief. The custom hallowed by age, of tying the knees together when this accident occurs, using disinfectant vaginal irrigations, and hoping for the best, is, I grant, in many cases followed by no immediate illeffects; but when now and again, as inevitably they must, the torn surfaces become sodden and ashy grey surfaced, the precursors of puerperal septicœmia, then probably it flashes across our minds that had modern surgical ideas been imported into the case, it might have had a different ending. There are certain patients in whom from a weakened condition of the tissues, due either to a cachexia-sucb, for example, as syphilis or local inflammatory changes-lacera. tions are unavoidable. Occupying a chief position amongst the causes is the unskilful use of the forceps. Wielded by strong hands, regarding not in what direction traction is being made, they are an instrument powerfal for evil. Conversely, their intelligent use in correcting a malposition, diverting misdirected force, or supplementing feeble propulsive efforts, gives them a place amongst the most valued resources of our art. The element of time is a very important one in ensuring a successful termination to the second stage of labour. In rapid labours there is neither the gradual moulding of the presenting part so necessary, nor is there that due accommodation of the maternal passages so essential to their integrity. As before incidentally mentioned, long-continued pressure upon the maternal tissues, by initiating necrotic changes and subsequent loss of substance, often brings about this accident. So also do small and deformed pelves, malpresentations, cicatricial contractions, and rigidity of the vulvar outlet. When alluding to the injury likely to follow rapid labours, I should have mentioned in this connexion the harmful effect of giving, as is frequently done in a routine fashion, ergot. It is impossible to gauge or control its power upon the uterine muscular fibres, and it cannot be doubted that in many cases it has been followed by the consequences we are considering.

The causes above enumerated find their strongest expression in primipare. The influence which this accident has upon the health of the lying-in woman naturally is divided by time into the immediate and remote, and of the former puerperal septicæmia occupies the premier position. The richness with which the peri-vaginal tissue is endowed with lymphatics and veins offers, once a breach of tissue is accomplished, easy access for the imbibition into the systemic circulation of septic materials. There are few who now cling to the specificity of puerperal fever, but rather look upon it as a blood dyscrasia, having for its exciting cause an autogenetic and heterogenetic source. And whether looked at by the light of modern uterine pathology or clinical experience, it must be confessed that in most instances a probably unnoticed baring and laceration of the absorbent vessels has been the fons et origo mali. The vitiated secretions from torn and bruised surfaces, and under certain conditions even the lochial discharges, doubtless exercise a toxic influence upon the parturient woman, and it is to this view of the majority of examples of puerperal fever the medical opinion of the present day is tending, and upon which must follow practice fraught with nothing but benefit to the community. The acceptance of the principle by the profession at large, that every tear of the maternal passages should be treated according to modern surgical procedure, will do very much towards reducing childbed mortality. Among recent writers on the subject there is none who from the commanding position which be occupies, can speak with greater anthority than Dr. Thomas, who, in an address before the New York Academy of Medicine on Dec. $6 \mathrm{th}, 1883$, with convincing eloquence demolished the specific theory, and showed how in most cases the inception of puerperal septicemia was traceable to the mal-influence of lesions of the genital tract.

Leaving this, which, after all, is debateable ground, it must be conceded by everyone familiar with the subject that the presence of perineal lacerations interferes with uterine and vaginal involution, laying thereby the seeds of future pelvic trouble. Of the remote effects of these rents there is some divergence of opinion, hinging as it does in great measure on the part which the perineum plays in the support of the uterus. Doubtless everyone sees now and again cases even of complete procidentia with perfect perineal bodies, but these are nothing to the large number applying for relief with varying degrees of uterine prolapse and histories and evidences of perineal lacerations. The rupture to any extent of the muscular conjunction which takes place at the perineum must, by interfering with the solidarity of the sacral 